\title{
Variability in Road Runoff Pollution by Polycyclic Aromatic Hydrocarbons (PAHs) in the Urbanized Area Adjacent to Biscayne Bay, Florida
}

\author{
Diana Mitsova ${ }^{1}$, Jaap $\operatorname{Vos}^{1}$, Piero Gardinali ${ }^{2}$, Inna Stafeychuk ${ }^{1}$ \\ ${ }^{1}$ School of Urban and Regional Planning, Florida Atlantic University, Fort Lauderdale, USA; ${ }^{2}$ Department of Chemistry \& Biochem- \\ istry and Southeast Environmental Research Center (SERC), Florida International University, North Miami, USA. \\ E-mail:dmitsova@fau.edu,gardinal@fiu.edu
}

Received September $8^{\text {th }}, 2011$; revised October $14^{\text {th }}, 2011$; accepted November $17^{\text {th }}, 2011$.

\begin{abstract}
Polycyclic aromatic hydrocarbons (PAHs) were consistently documented in the sediments of the canals draining into Biscayne Bay. The study examines the contribution of urban runoff to PAHs discharges. Subtropical climatic conditions associated with prolonged dry seasons often exacerbate the problem of PAHs pollution as the initial storms of the wet season wash off pollutants accumulated over time. Road runoff samples were collected at two sites with different levels of traffic at the end and at the beginning of the wet season. Storm-event mass first flush was found to occur inconsistently. Higher levels of PAH pollution were found at both sites after an extended dry season. The Kendall's tau test used to measure the association between antecedent dry days and flow-weighted PAH concentrations were found to be statistically significant. The correlation between traffic intensity and PAHs levels in road runoff was found not to be statistically significant. High-molecular-weight PAHs originating in vehicle exhaust emissions appeared to dominate PAH concentrations in road runoff. The Friedman's test showed overall similarity in PAHs composition profiles between seasons with the exception of low-molecular weight PAHs.
\end{abstract}

Keywords: PAHs, Storm-Event Mass First Flush, Seasonal Variability, Annual Average Daily Traffic

\section{Introduction}

Polycyclic aromatic hydrocarbons (PAHs) are an assembly of over 100 semi-volatile organic compounds consisting of two or more fused benzene rings. They are commonly present in the urban environment and are often associated with a variety of diffuse natural and anthropogenic sources. PAHs vary in prevalence, toxicity and persistence in the environment. Higher molecular weight PAHs often associated with by-products of incomplete combustion are considered persistent organic pollutants (POPs) with relatively long half-lives in soils and sediment [1]. Awareness of the omnipresence of PAHs and their often elevated background levels in highly urbanized areas has prompted a number of recent studies [2-6] as well as increased attention from the USEPA and the Agency for Toxic Substances and Disease Registry (ATSDR) [7].

Pollutant discharges carried by stormwater runoff to Biscayne National Park and Aquatic Preserve are known to include suspended solids, nitrogen, phosphorus, cadmium, copper, lead, zinc, oil, grease, litter and organic waste [8-12]. The presence of aliphatic and aromatic hydrocarbons in the sediments of Biscayne Bay has been investigated since the 1980s. Corcoran et al. [9] completed The Biscayne Bay Hydrocarbon Study, a largescale analysis of the spatial distribution of the hydrocarbons in estuarine sediments. Cantillo et al. [11] continued the investigation of PAHs content in mollusks and sediments in South Florida as part of the NOAA National Status and Trends Program. Earlier studies consistently documented the presence of PAHs in sediments of Miami River and the Biscayne Bay $[9,11,13]$. Comprehensive recent studies found various levels of PAHs in sediment samples collected from the beds of the canals and lower Miami River in Miami-Dade County [13-15]. Although the extent of PAH contamination of the sediments of Biscayne Bay is well established, the contribution of urban runoff as a source of origin of PAHs requires further investigation.

PAHs tend to adhere to particles and are typically found in both dissolved and particulate phases in urban runoff. 
Despite low concentrations, urban runoff could deliver considerable amounts of oil and grease to the aquatic environment exclusive of spills [16]. Recent increases in PAH input to aquatic sediments in urban areas were related to PAHs releases from an increasing number of mobile sources [17]. Increased traffic activity was linked to high levels of PAHs in urban stormwater [6,16,18-22].

The literature suggests that the presence of low-molecular weight (LMW) PAHs in runoff is indicative of petrogenic source of origin (i.e., crankcase oil drips, spills, etc.), while the presence of high-molecular weight (HMW) PAHs is associated with potential pyrolytic sources (i.e., vehicle exhaust emissions, burning of organic matter, etc.) $[5,6,16,18]$. Several recent studies have given priority to pyrolytic over petrogenic sources $[5,6,20]$. Stein et al. [5] found that pyrolytic sources dominate urban runoff over petrogenic sources in the majority of storms irrespective of land use. Studies also consistently documented that more than $70 \%$ of total PAHs in urban runoff consisted of high-molecular weight PAHs suggesting deposition associated with vehicle emissions and other airborne inputs as dominant sources of PAHs in stormwater and sediments $[5,17,23]$.

Most studies agree that the main driving force contributing to PAH levels include traffic intensity [21], land use [16,23,24] and seasonality [4]. Hoffman et al. [23] used concentration and flow data to develop loading factors as a function of land use and average daily traffic volume. The study found that PAHs discharge rates from highways and industrial land use were higher than those from residential areas. Menzie et al. [20] found that commercial and residential land use dominate PAHs releases hypothesizing that secondary sources such as spills of oil and grease enhanced the flux from atmospheric deposition. Stein et al. [5] found a uniform distribution of the total PAHs flux throughout the urbanized region of Los Angeles observing that there was no significant difference in PAHs concentrations in runoff generated from various urban land uses.

A pollutant first flush is defined relative to the pollutant mass carried out by the initial fraction of the runoff volume [2-6,25,26]. Estimation of a storm first flush involves computing the cumulative pollutant mass discharge in the initial portion of the runoff volume $[2,3]$. Most studies suggest that estimates of the first flush pollutant emissions should be based on the initial $20 \%$ to $40 \%$ of runoff volume $[26,27]$. Bertrand-Krajewski et al. [26] characterized the occurrence of a first flush as 80 percent of the pollutant mass emitted in the initial 30 percent of stormwater runoff volume. Stenstrom and Kaynahian [2] suggested a quantitative measure based on the mass first flush ratio (MFF). MFF allows plotting the normalized cumulative mass discharge against the cu- mulative runoff volume. The inflection point at which the slope of the curve exceeds 45 percent is associated with the occurrence of a first flush event [2,3].

Several studies found that the estimation of a first flush may be confounded by several factors including the size of the drainage area [28], site characteristics [4], rainfall patterns $[6,18,23]$ and antecedent dry days $[5,6,29]$. The size of the drainage area was found to be negatively correlated with the storm first flush. A storm first flush is rarely reported for large watersheds [28]. Lee and Bang [29] and Zhang et al. [6] found no significant relationship between pollutant discharge and the number of antecedent dry days. However, in areas where the annual distribution of rainfall events is roughly uniform, accumulation of pollutants on the ground may not be as significant as in areas characterized by extended dry periods. Previous studies found that climatic conditions associated with prolonged dry seasons tend to increase seasonal discharges of pollutants to receiving waters $[2,4,5]$. During these periods without or very little precipitation various hydrocarbon species, emitted from vehicle exhaust or released as a result of spillage, accumulate over pervious and impervious surfaces [5]. Significant pollutant loadings delivered to aquatic environments as a result of the seasonal first flush may affect the productivity of the estuarine ecosystems which harbor many fish and shellfish species, provide spawning grounds, nurseries and shellfish beds, and secure a vital link between primary producers and larger marine organisms [16,30]. Seasonal first flush is computed similarly to the storm first flush when both flow and pollutant concentrations data are available [4]. In most cases, however, these data records are difficult to obtain on a consistent basis. Stenstrom and Kayhanian [2] suggested using normalized precipitation data instead of flow rate to determine seasonal first flush.

The primary objective of the study was to examine the variability in PAHs distribution in runoff from roads adjacent to commercial land use. The sampling and analytical approaches were designed to address research questions related to storm-event and seasonal variability in PAHs concentrations; existence of a mass first-flush; variability in flow-weighted mean concentration, massloading rate and $\mathrm{PAH}$ composition profiles between storm events and seasons; determine PAHs source of origin, and assess the impact of average daily traffic on PAHs concentrations in road runoff.

\section{Materials and Methods}

\subsection{Study Area}

Biscayne Bay estuary covers approximately 430 square miles along the lower east coast of Florida (Figure 1). The northern portion of the Bay is designated an Aquatic 
Preserve (under the Florida Aquatic Preserve Act of 1975). Biscayne National Park encompasses the southern portion of the Bay. The study area is characterized by a warm and humid subtropical climate driven by wet and dry seasons, convective storms and tropical cyclones [31]. The wet season extends from June through September and the dry season from October through mid-May. The annual average temperature is $75.9^{\circ} \mathrm{F}$. The annual precipitation is $142 \mathrm{~cm}$. The wettest month is June followed by August and September [32]. Individual years may significantly differ from this pattern. The area is characterized by lowlying gently sloped topography and a complex hydrology resulting from the interactions of porous substrate geology, freshwater aquifer systems, and estuarine and marine environments. Biscayne Bay receives freshwater inflows from the Everglades ecosystem through the Biscayne Bay catchment area covering approximately 940 square miles. The area drains into the Bay through a

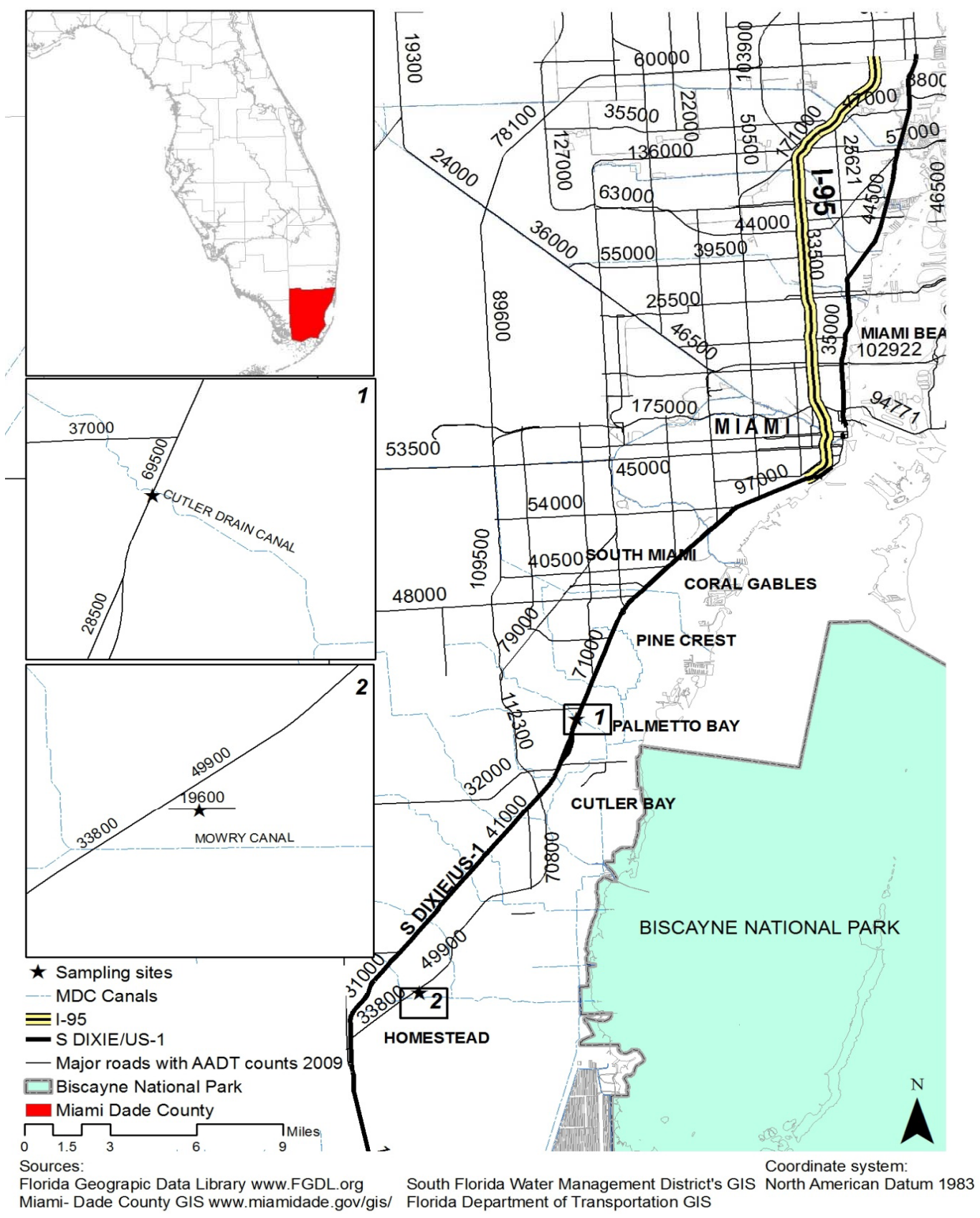

Figure 1. Study area and sampling sites. 
system of freshwater canals. The location of Biscayne Bay along the Miami metropolitan area with a current population of nearly 5.5 million increases its exposure and susceptibility to a wide variety of contaminants [12]. Population growth and continuing coastal development have affected the water quality of Biscayne Bay and the productivity and richness of its estuarine communities [12].

Major transportation routes in the area include I-95, South Dixie Highway/Federal Highway 1 (S Dixie Hwy/ US1) and the Florida Turnpike. I-95 merges into South Dixie Highway south of Miami Downtown and consequently all traffic southbound is directed towards $\mathrm{S}$ Dixie/US-1 resulting in heavy traffic volumes. The road has six lanes with major intersections every $1300-2000$ feet. The maximum 2009 annual average daily traffic (AADT) in the study area reached 147,000. The 2009 average AADT for Miami-Dade County was 22,500 while the median was 30,000 [33].

In selecting the appropriate sampling locations, eleven preliminary sites were investigated. Most areas with outfalls had points of discharge under water due to high water table, or under pavement and fixtures. In addition, the South Dixie Highway sites had slab-covered trenches completely open on the bottom, in contact with the aquifer. Under these conditions, collecting samples at outfalls could not rule out mixing urban runoff with soil and groundwater, and therefore decision was made to collect samples at intake chambers. Two sites were selected based on the following criteria: 1) absence of known sources of PAHs (e.g., gas stations, recently resurfaced parking lots, oil storage tanks, railroads, etc.); 2) magnitude of AADT counts; 3) homogenous land use; 4) proximity to Biscayne Bay; and 5) accessibility. In 2009, Site 1 located near the C-100 canal on S Dixie/US-1 highway (Figure 1), had an annual average daily traffic of 69,500 vehicles per day [33]. The site is representative of the highly urbanized northern part of the study area. Site 2 located near the intersection of the 312th Street and Homestead Hospital Plaza Exit of the Florida Turnpike in the City of Homestead, Florida, had an average annual daily traffic of 19,600 vehicles per day. The second site is representative of the less developed southern part of the study area. Both sites are adjacent to commercial land use.

\subsection{Sampling Design}

The sampling procedures were in compliance with the NDPES Storm Water Sampling Guidance [34]. The document recommends collecting oil and grease contaminated water in $1 \mathrm{~L}$ amber certified glass containers manually due to the tendency of oil and grease to adhere to surfaces [34]. Automatic samplers were not used to avoid transferring grab samples from one container to another. Field collected samples were stored at $4^{\circ} \mathrm{C}$ in the dark until arrival to the laboratory. Two samples during each storm event were collected simultaneously as part of the quality assurance procedures.

Rainfall intensity was measured with Global Water's RG200 Rain Gauge (a tipping bucket). The resolution of the tipping is $0.254 \mathrm{~mm}$ with accuracy of $3 \%$. The flow rate was estimated based on field measurements of flow velocity. Each time when a measurement of velocity was taken, depth and width of the flow were measured and recorded. Archived precipitation data were collected from weather stations located in Miami, Palmetto Bay, Cutler Bay and Homestead.

\subsection{Laboratory Analysis and Quality Assurance}

Road runoff samples were analyzed by gas chromatography-mass spectrometry (GC/MS) and fluorescence spectroscopy (FS). The analyses were conducted by the Environmental Analysis Research Laboratory, Southeast Environmental Research Center (SERC), Department of Chemistry \& Biochemistry at Florida International University. Water samples (1-Liter) were extracted by liquid-liquid extraction against methylene chloride using a modification of EPA 3510 as described by EARL-SOP2000-103.1. Sediment samples were extracted by accelerated solvent extraction (ASE) using modifications of EPA method 3545 . Sediments (30 g) were chemically dried, packed into stainless steel cells and extracted using a DIONEX ASE 200 instrument with dichloromethane at a temperature of $100^{\circ} \mathrm{C}$ and a pressure of $1500 \mathrm{psi}$. After concentration, samples were processed for either FS or GC/MS. Sample extracts used for FS $(5-\mathrm{mL})$ were placed in a $1 \mathrm{~cm} \times 1 \mathrm{~cm}$ quartz cell and quantitated against an oil standard at an excitation wavelength of $315 \mathrm{~nm}$ and emission wavelength of $415 \mathrm{~nm}$ using a Horiba Fluoromax 4 spectrophotometer. The results are expressed in $\mathrm{mg}$ of oil equivalents per liter of sample. Extractions of GC/MS were amended with the appropriate per-deuterated surrogate standards, subjected to column chromatography cleanup using silica and alumina and, after final concentration analyzed by GC/MS under electronic impact (EI) mode in selected ion monitoring (SIM). Analytes were separated on a 30-meter, $0.25 \mathrm{~mm}$ i.d., 0.25 $\mu \mathrm{m}$ film thickness RTX5-MS fused silica capillary column using a modified EPA 8270 method as described in EARL-SOP-2000-109.1. A six-point calibration curve in the range of 0.02 to $4.0 \mu \mathrm{g} / \mathrm{L}$ was used. Statistical method detection limits were between 2 and $10 \mathrm{ng} / \mathrm{L}$ depending on the PAH structure and molecular weight.

Batch QA/QC included analysis of blanks, matrix fortified samples and sample duplicates. All QA/QC para- 
meters were within the allowable criterion established by the method. Water and sediment samples were spiked with napthalene- $\mathrm{d} 8$, acenapthene- ${ }_{\mathrm{d} 10}$, phenanthrene- $\mathrm{d} 10$, chrysene- $_{\mathrm{d} 12}$, perylene- $\mathrm{d} 12$ as surrogate compounds. Based on $\mathrm{PAH}$ extended isomers in water samples surrogate recoveries for napthalene- $\mathrm{d} 8$ ranged from $60.5 \%$ to $84.5 \%$, for acenapthene- ${ }_{\mathrm{d} 10}$ from $64.4 \%$ to $93.8 \%$, for phenanthrene-d10 from $70.7 \%$ to $94.8 \%$, for chrysene-d 12 from $58.1 \%$ to $126.3 \%$, and for perylene- $\mathrm{d}_{12}$ from $57.9 \%$ to $119.4 \%$. For total PAHs, surrogate recoveries were $75.2 \%$ for water samples collected during the storm event on $09 / 29 / 2010,75.4 \%$ for the storm event on $12 / 18 / 2010$, $113.4 \%$ for the storm event on $04 / 30 / 2011$, and $100.7 \%$ for the storm event on 05/15/2010. Based on PAH extended isomers in sediment samples, surrogate recoveries for napthalene-d 8 ranged from $51.1 \%$ to $61.6 \%$, for acenapthene- ${ }_{\mathrm{d} 10}$ from $63.5 \%$ to $75.3 \%$, for phenanthrene- ${ }_{110}$ from $75.4 \%$ to $98.3 \%$, for chrysene- ${ }_{12}$ from $76.4 \%$ to $114.7 \%$, and for perylene- ${ }_{\mathrm{d} 12}$ from $72.7 \%$ to $101.2 \%$.

\subsection{Data Analysis}

The variability of PAHs concentrations during a specific storm was examined by constructing time versus concentration plots. Measured PAH concentrations were plotted against flow rate to create a pollutograph for each storm. The first-flush phenomenon was analyzed by computing the mass first flush ratio (MFF) and constructing cumulative mass curves in which cumulative PAH mass emissions were plotted against cumulative runoff volume $[2,5,6] . \mathrm{MFF}_{i}$ was calculated using Equation (1):

$$
\operatorname{MFF}_{i}=\frac{\left[\int_{0}^{1} C_{i}(t) Q_{i}(t) \mathrm{d} t\right] / M}{\left[\int_{0}^{1} Q_{i}(t) \mathrm{d} t\right] / V}
$$

where $\mathrm{MFF}_{i}$ is a dimensionless ratio ranging from 0 to 1 , $i$ represents the point in time when a measurement is taken, $C_{i}(t)$ is the measured concentration at the time of the $i$-th sample, $Q_{i}(t)$ is the runoff volume as a function of time, and $M$ and $V$ are the total pollutant mass emitted and the total runoff volume, respectively [2].

Flow-weighted mean concentration (FWMC) and massloading rate (MLR) were computed for each storm to obtain estimates of the total pollutant mass delivered to a water body for a specific period of time. FWMC is calculated as the total load for a time period divided by the total discharge for that period (Equation (2)):

$$
\mathrm{FWMC}=\frac{\sum_{1}^{n}\left(C_{i} \times Q_{i} \times \Delta t\right)}{\sum_{1}^{n}\left(Q_{i} \times \Delta t\right)}
$$

where $n$ is the number of samples per storm event, $C_{i}$ is the measured concentration in the $i$-th sample, and $Q_{i}$ is the instantaneous time-variable runoff volume at the time of the $i$-th sample.

The mass-loading rate is the rate of delivery of a particular pollutant to the point of discharge. Following Zhang et al. [6] we calculate the mass loading rate as follows (Equation (3)):

$$
\operatorname{MLR}=\frac{\sum_{1}^{n}\left(C_{i} \times \Delta Q_{i} \times \Delta t_{i} \times P_{s}\right)}{\sum_{1}^{n}\left(R_{i} \times T \times A\right)} \times 10^{-6}
$$

where the MLR is the mass-loading rate in $\mathrm{kg} / \mathrm{km}^{2} /$ season; $C_{i}$ is the measured concentration in the $i$-th sample; and $\Delta Q_{i}$ is the change in instantaneous time-variable runoff volume at the time of the $i$-th sample (L/min); $\Delta t_{i}$ is the elapsed time between two samples ( $\mathrm{min}) ; T$ is the storm event duration (min); $R_{i}$ is the rainfall intensity $(\mathrm{mm} / \mathrm{min}) ; P_{s}$ is the average seasonal precipitation for the dry and wet seasons, respectively; and the $A$ is the washed-off area $\left(\mathrm{m}^{2}\right)$.

Seasonal flush analysis requires information on the runoff produced at each site over the entire season together with measured concentrations [4,35]. Stenstrom and Kayhanian [2] suggest using rainfall data when runoff data are not available in order to create a common parameter against which measured concentrations can be plotted. In that case, the normalized cumulative rainfall curve is used to estimate the fraction of the discharged pollutant and derive conclusions about the occurrence of a seasonal flush. This type of analysis was beyond the scope of this investigation since it required additional samples collection during both the wet and dry seasons. We used panel charts to plot rainfall, flow and total petroleum hydrocarbons to evaluate the relationship between seasonal daily rainfall, antecedent dry days and measured concentrations.

The variability in PAH composition profiles was examined using the Friedman's statistical test, a non-parametric equivalent of the two-way ANOVA. The PAHs composition profiles were also analyzed to determine the dominant source of the compounds found in road stormwater runoff. The Kendall's tau correlation coefficient was used to measure the association between PAHs concentrations and the annual average daily traffic, and between PAHs concentrations and the antecedent dry days.

\section{Results and Discussion}

\subsection{Storm Events and Sampling}

In 2010-2011, South Florida experienced an extended and drier than normal dry season with a total rainfall deficit of $-27 \mathrm{~cm}$ which is $25 \%$ to $50 \%$ below the aver- 
age October to May rainfall (normally, between 38 to 53 $\mathrm{cm}$ ) [32]. The rainfall deficits, as shown on Figure 2, were consistent with the persistence of the cold phase of ENSO (El Niño/La Niña Southern Oscillation) over the equatorial Pacific. La Niña began in July 2010 and continued to exert strong influence over the weather patterns in South Florida through June 2011 [36]. These conditions, known as La Niña, tend to exacerbate drought in Florida and the Southeast [36].

The first set of samples was collected on September $29^{\text {th }}, 2010$, followed by another sampling on December $18^{\text {th }}, 2010$. The results from the initial sampling (carried out at the end of the wet and beginning of the dry season) were used as benchmarks to compare the changes occurring in $\mathrm{PAH}$ concentrations in urban runoff at the end of the dry season. The same sites were sampled again on April 30 ${ }^{\text {th }}, 2011$ and May 15 ${ }^{\text {th }}, 2011$. Total PAHs and individual PAHs concentrations were determined from samples collected at intake chambers. Runoff samples were collected at 15 - 30 minutes intervals. Lee et al. [37] used short (3 - $5 \mathrm{~min}$ ) intervals before the peak flow was reached and then sampled every 15 - $30 \mathrm{~min}$. Hoffman et al. 1984 suggested sampling every 30 minutes and more often when flow rates are rapidly changing and high. Overall, 45 water samples were collected.

Eighteen samples were collected during two storms at the end of the wet season (storms of 09/29/2010 and 12/
18/2010). Twenty seven samples were collected at the end of the dry season of 2010-2011. Overall, twenty three water samples were collected on sampling Site 1 (S Dixie/US-1) (storms of 09/29/2010 and 05/15/2011) and twenty two water samples were collected on sampling Site 2 (storms of 12/18/2010 and 05/15/2011). One reference sample per batch was collected for quality assurance and quality control purposes. The number of samples and the sampling location were dictated by the duration and occurrence of the storm events. The samples were analyzed for total petroleum hydrocarbons using fluorescence spectroscopy. In addition, forty individual PAHs were extracted and separated by gas chromatography - mass spectrometry method. Sixteen of the quantified PAHs were on the EPA's Priority Pollutant List.

\subsection{Pollutograph and Mass First Flush Analysis}

A pollutograph plots concentrations relative to flow rate and time [28]. Pollutographs of the sampled storm events are shown on Figure 3. All sampled storm events were characterized by pulses of va- rying intensities whereas in most cases, higher rainfall in- tensities occurred over the earlier portions of the storm. With one exception, the highest PAH concentrations were observed at the beginning of each storm event generally decreasing across the storm duration. As the pollutographs indicate, lower flow conditions appeared to correlate with higher concentra-

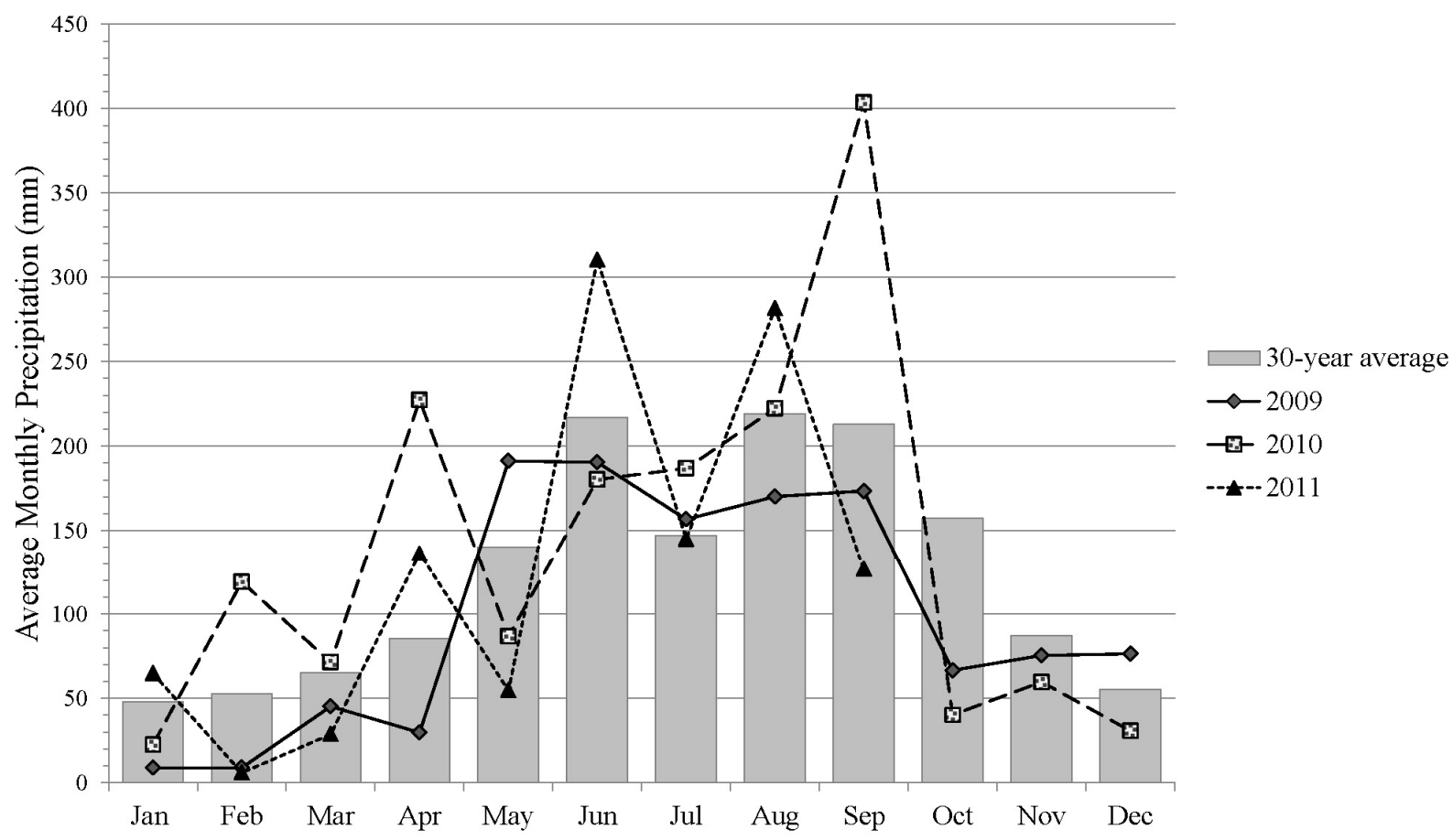

Figure 2. Observed 30-year average (1971-2000) and average monthly precipitation in Miami from January 2009 through June 2011 (Data Source: NOAA-NWS 2009; FSU Florida Climate Center). 

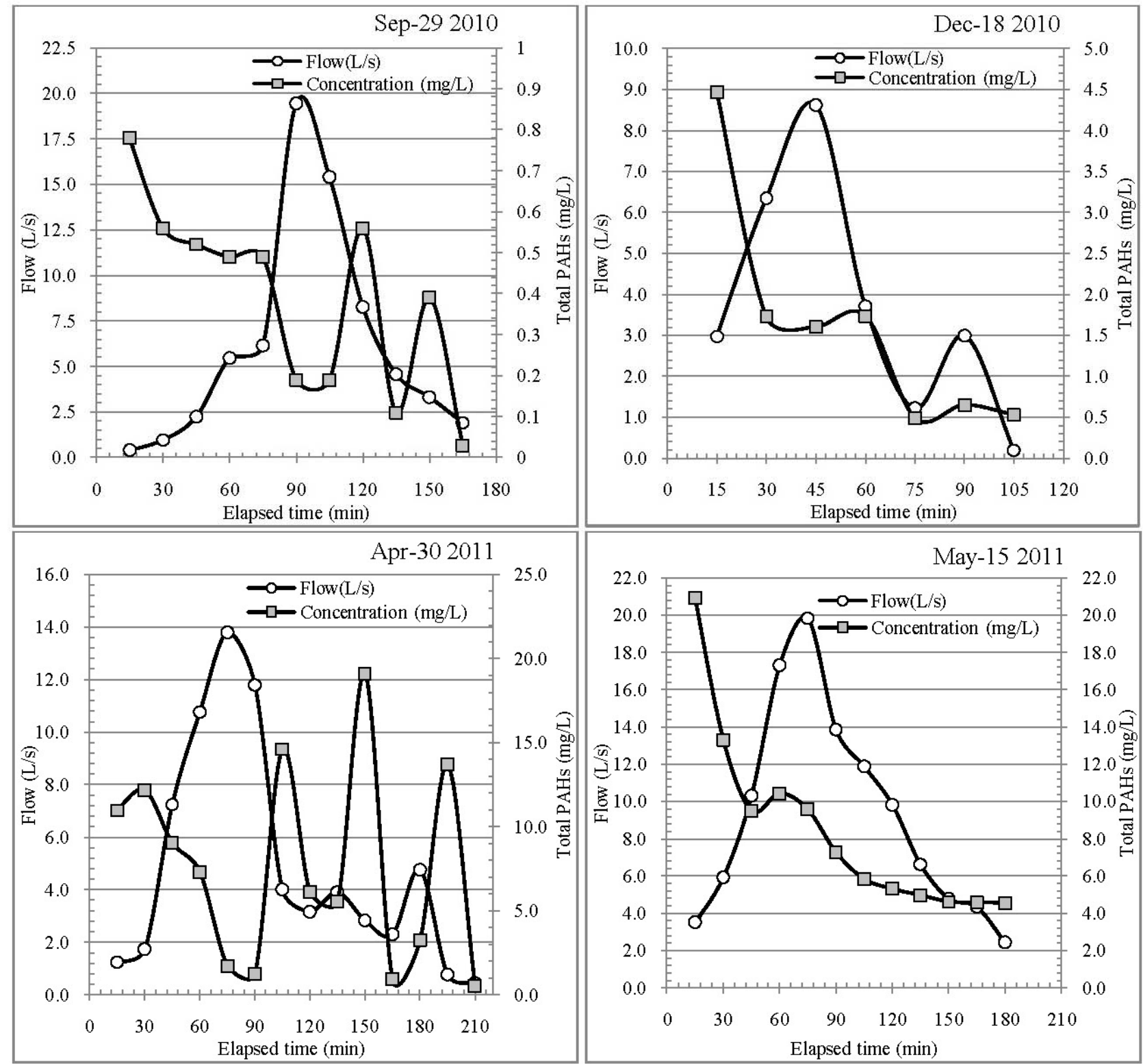

Figure 3. Total PAH concentrations and flow rate as a function of elapsed time.

tions. As Hoffman et al. [18] suggest, this result can be attributed to the effect of dilution. Greater variability was observed during the storm event of April 30, 2011, when peak pollutant concentration occurred at the mid-point of the storm event. The storm of April 30 was characterized by an initial peak in rainfall intensity followed by three weaker pulses of rain. The distribution of rainfall intensities across the storm duration appeared to contribute to the lack of predominant pattern of PAH discharges during this event.

Lee et al. [35] discuss the effect of rainfall patterns on measured concentrations emphasizing the importance of rainfall intensity for mobilization of suspended solids. Zhang et al. [6] observe that the distribution of peak rainfall intensity throughout the storm duration has an impact on the time-concentration series. Rain pulses occurring at peak intensities during various portions of the storm event can mobilize additional wash-off material affecting the variability in measured concentrations. Krein and Schorer [17] show that washed-off material could be mobilized and remobilized several times before reach- ing the storm drainage system, thus influencing PAH emission rates.

A pollutograph is helpful in understanding the rela- 
tionship between measured concentrations and flow rates as a function of time but does not provide sufficient information regarding the existence of a first flush event. A first flush is generally defined as the fraction of the pollutant mass carried out by the initial fraction of the runoff volume. The higher the proportion of total pollutant mass discharged within the initial proportion of the total runoff volume, the higher the magnitude of the first flush. The $45^{\circ}$ reference line indicates where the fraction of the total mass is equivalent of the fraction of the total runoff volume. It is assumed that no first flush is observed if the fraction of the total mass descends below the $45^{\circ}$ reference line, equals points on the line, or ascends slightly above it [2].

Figure 4 suggests that mass first flush occurred inconsistently throughout the sampled storm events. The cumulative mass curve implies a low mass first flush for the storm event on September $29^{\text {th }}, 2010$. The low mass fist flush during this event can be attributed to the observed rainfall patterns and antecedent dry days. Since the month of September was the wettest month of 2010 with nearly $19 \mathrm{~cm}$ of rain above the monthly average, the continuous wash-off did not allow sufficient time for pollutants to accumulate over impervious surfaces. Thus, measured concentrations were considerably lower compared to those found in samples preceded by an extended dry period. They were also distributed almost evenly throughout the duration of the storm.

A low mass first flush was observed also during the storm event of April 30 when the peak concentration occurred during the latter component of the storm. During this storm event approximately $48 \%$ of the total pollutant mass was found in the first $30 \%$ of total runoff volume. Figure 4 indicates that a moderate mass first flush occurred during the storm events of December 18, 2010, and May 15, 2011. For these two medium-size storms, there was approximately 60 percent of the PAHs total mass load in the initial 30 percent of the runoff volume. Previous studies suggested a consistent pattern of observing a moderate mass first flush from small sites with homogenous land use [38]. A moderate to high first flush is typically observed from highly impervious commercial sites [38].

\subsection{Variability in PAHs Concentrations between Wet and Dry Seasons}

Figure 5 shows the difference between measured concentrations $(\mathrm{mg} / \mathrm{L})$ at the end of the wet, the beginning of the dry season, and the beginning of the wet season. It also displays antecedent dry days, daily rainfall $(\mathrm{mm})$ from September 2010 through May 2011, measured rain-fall $(\mathrm{mm})$, and flow rate $(\mathrm{L} / \mathrm{s})$ during the sampled storm events. Elapsed time between storms appeared to correlate positively with increases in PAH concentrations. Plotting seasonal rainfall against measured concentrations indicate that higher PAH concentrations were observed after longer dry periods preceding the storm events. The lowest levels of total petroleum hydrocarbons were measured at the end of September (i.e., end of the wet season). Daily rainfall data suggest that the month of October was

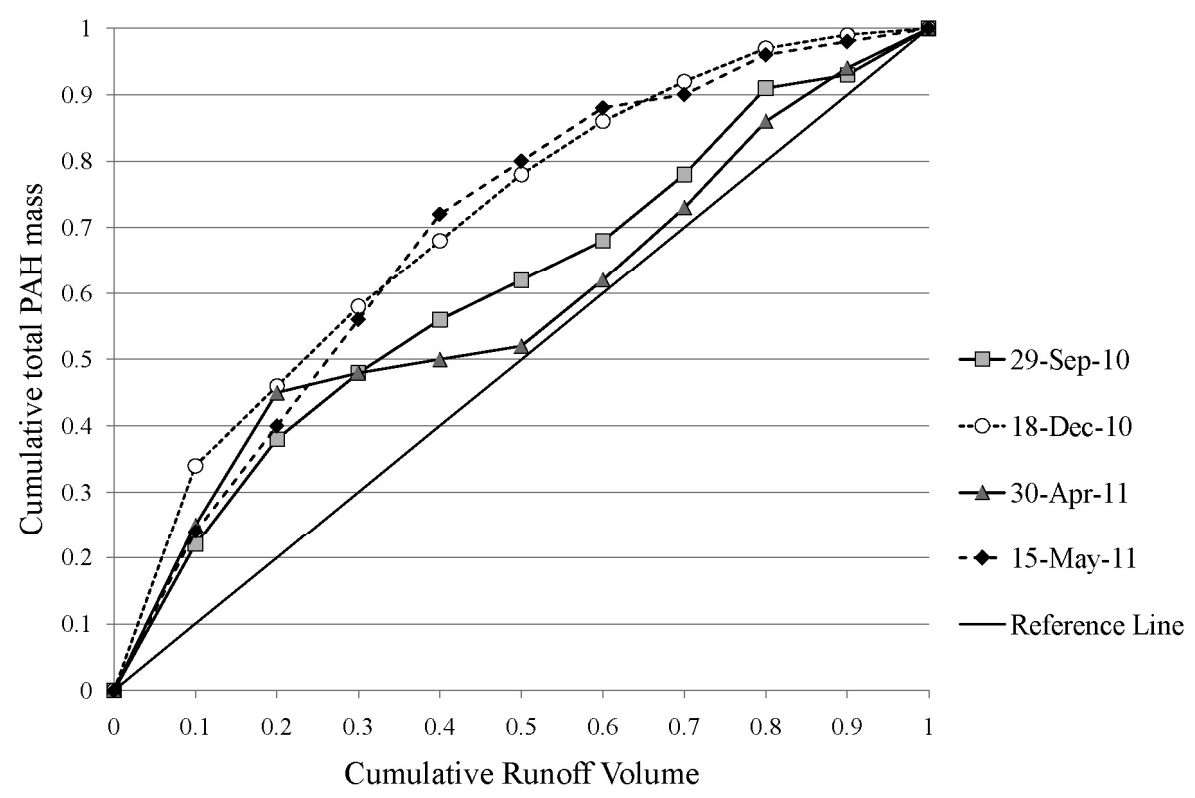

Figure 4. Fraction of a cumulative mass loading for total petroleum hydrocarbons (TPH) as a fraction of the cumulative road runoff volume (dimensionless). 

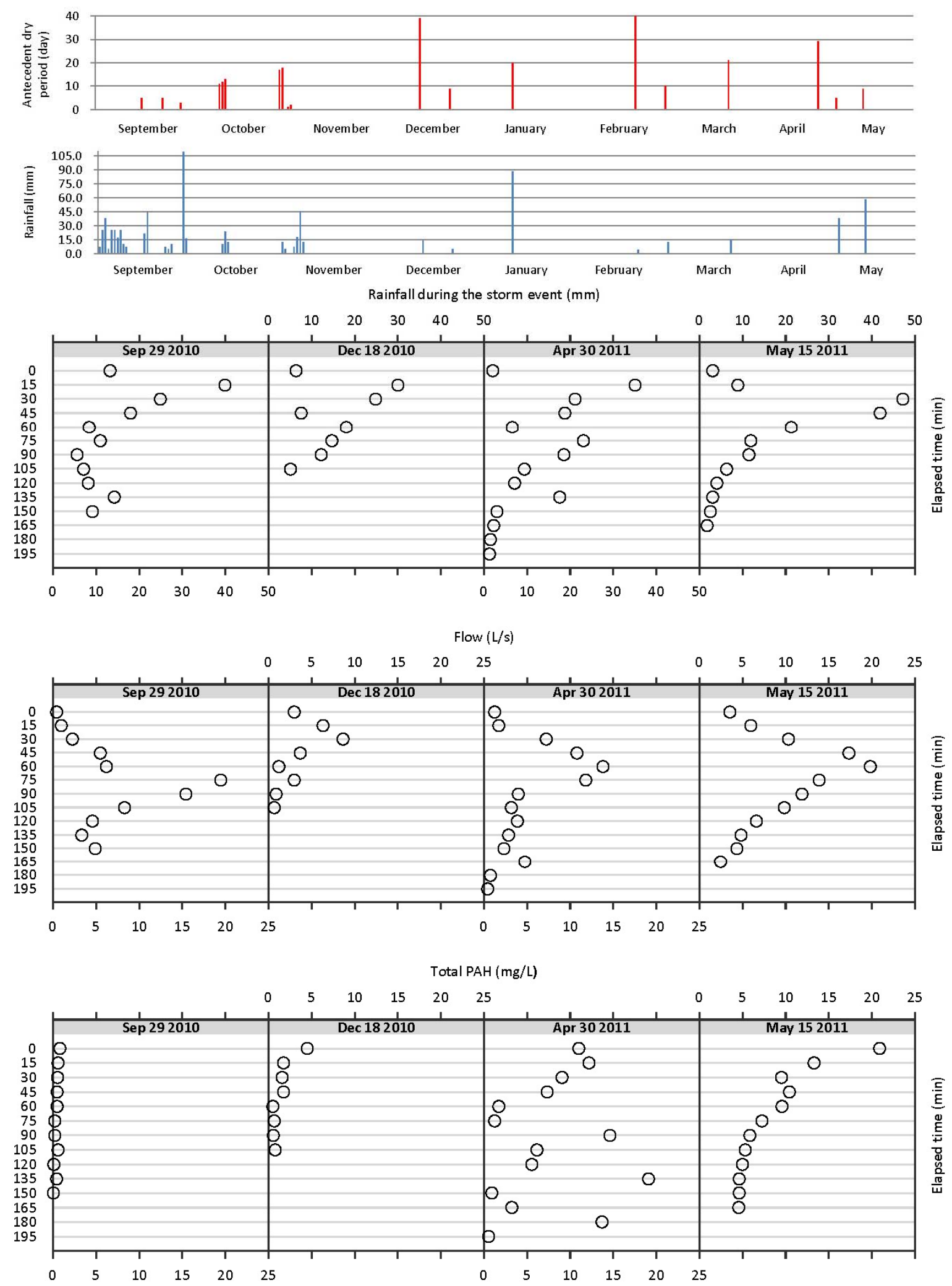

Figure 5. Panel chart of antecedent dry days and daily rainfall (mm) September 2010 - May 2011, incremental precipitation during storm events $(\mathrm{mm})$, flow $(\mathrm{L} / \mathrm{s})$ and total PAH concentrations $(\mathrm{mg} / \mathrm{L})$. 
significantly drier than normal with a deficit of $-11.7 \mathrm{~cm}$ below the monthly average, while November and December recorded deficits of -2.7 and $-2.5 \mathrm{~cm}$ below the monthly average, respectively. The rainfall totals for the months of February and March were again below average with $-4.7 \mathrm{~cm}$ and $-3.6 \mathrm{~cm}$, respectively. After the occurrence of relatively dry conditions in October and November, the samples collected in mid-December contained higher total PAH concentrations. The total PAH concentrations measured in samples collected in April and May 2011 after an extended and drier than normal season were considerably higher suggesting that accumulation of pollutants played a role in increased total PAH levels. These findings appear to be consistent with the results of previous studies conducted in climates with wet/dry seasons. Stein et al. [5] associated increasing PAH mass-loading rate to longer antecedent dry periods due to related build-up of pollutants over pervious and impervious surfaces.

Table 1 shows that the lowest event-based FWMC $(0.310 \mathrm{mg} / \mathrm{L})$ was estimated for the site with higher traffic volume during the storm event of September 30, 2010. A FWMC of $1.8 \mathrm{mg} / \mathrm{L}$ was estimated for the site with the lower traffic intensity during the storm event of December 18, 2010. Overall, the estimated FWMCs at the end of the dry season were found to be considerably higher $5.8 \mathrm{mg} / \mathrm{L}$ for the storm event of April 30, 2011 (for the site with lower traffic intensity) and $8.5 \mathrm{mg} / \mathrm{L}$ for the storm event of May 15, 2011 (for the site with higher traffic intensity). Table 1 also displays the results from the estimated partial flow-weighted mean concentrations for the first 30,60, 90, 120 and 150 minutes of the storm event. All sampled storms exhibited a similar pattern of declining partial FWMCs with each 30-minute interval. The only exception was the storm of April 30 in which a sharp increase in the partial FWMC at the beginning of storm was followed by a sharp decline over the second interval of 30 minutes, and again an increase in total
PAHs levels over the third and fourth 30-minute intervals. The partial FWMC at the end of the fifth 30-minute interval for the storm of May 15, 2011 was higher than the partial FWMCs for the remaining three storm events.

Kendall's tau testing the concordance between flowweighted mean concentrations and antecedent dry days yielded a Kendall's tau-a $=0.979$ with a $p$-value $=0.02$. From these results, we can conclude a strong positive statistically significant correlation between FWMCs and antecedent dry days. The Kendall rank coefficient was also used to test the null hypothesis of concordance between flow-weighted mean concentrations and annual average daily traffic. The test yielded a Kendall's tau-a $=$ -0.33 with a $p$-value of 0.26 . The test statistic did not show a statistically significant correlation between the two variables. From these results, we cannot reject the null hypothesis of mutual independence between FWMCs and traffic intensity. Higher levels of pollutant accumulation after a prolonged dry season appear to have a sizeable effect on PAH FWMCs.

Average seasonal precipitation for the dry and wet seasons was used to calculate the seasonal unit loading rate for total petroleum hydrocarbons. The end-of wet season unit loading rate for the road with a higher traffic volume was $0.589 \mathrm{~kg} / \mathrm{ha}\left(5.89 \mathrm{E}-03 \mathrm{~kg} / \mathrm{km}^{2}\right)$. The value is lower than the total PAHs mass-loading rate at the beginning of the dry season for the road with the lower traffic volume which was $1.34 \mathrm{~kg} / \mathrm{ha}\left(1.34 \mathrm{E}-02 \mathrm{~kg} / \mathrm{km}^{2}\right)$. The total PAHs mass-loading rate at the beginning of the wet season was $8.38 \mathrm{~kg} / \mathrm{ha}\left(8.38 \mathrm{E}-02 \mathrm{~kg} / \mathrm{km}^{2}\right)$ at the site with lower AADT counts and $21.57 \mathrm{~kg} / \mathrm{ha})\left(2.16 \mathrm{E}-01 \mathrm{~kg} / \mathrm{km}^{2}\right)$ at the site with higher AADT counts, respectively.

These findings suggest that at the end of the dry season and the beginning of the wet season higher PAH mass-loading rate was generated from the site with lower traffic volume, while at the end of the dry season higher $\mathrm{PAH}$ mass-loading rate was generated at the site with higher annual average daily traffic counts. The mass-load-

Table 1. Storm flow-weighted meanconcentrations (FWMCs), partial FWMCs at storm durations of 30, 60, 90, 120 and 150 minutes and total PAHs mass-loading rate $\left(\mathrm{kg} / \mathrm{km}^{2}\right)$.

\begin{tabular}{ccccc}
\hline Parameter & \multicolumn{3}{c}{ Storm Event } \\
\hline & Sep-29 2010 & Dec-18 2010 & Apr-30 2011 & May-15 2011 \\
Event FWMC (mg/L) & 0.310 & 1.809 & 5.826 & 8.491 \\
Partial FWMC30 (mg/L) & 0.793 & 2.353 & 14.576 & 16.718 \\
Partial FWMC60 (mg/L) & 0.695 & 1.043 & 1.934 & 13.079 \\
Partial FWMC90 (mg/L) & 0.289 & 0.919 & 7.401 & 5.978 \\
Partial FWMC120 (mg/L) & 0.392 & 0.452 & 6.141 & 4.805 \\
Partial FWMC150 (mg/L) & 0.328 & & 0.830 & 3.884 \\
Total PAHs mass-loading rate $\left(\mathrm{kg} / \mathrm{km}^{2}\right)$ & 0.006 & 0.013 & 0.084 & 0.216 \\
\hline
\end{tabular}


ing rate range is consistent with the findings of Stein et al. [5] for the range of total PAHs mass-loading rate measured on transportation land uses in Southern California. The results indicate than the antecedent dry days affect the build-up of pollutants and the subsequent massloading rate more than the annual average daily traffic. Stein et al. [5] found a strong relationship between PAH mass-loading rate and antecedent dry days suggesting that PAH fluxes in the late wet season may be influenced by wet deposition and other localized sources. Further investigation is required to improve the understanding of these factors.

\subsection{Sources of PAHs Origin in Road Runoff}

Several recent studies suggest that the deposition of urban aerosols associated with combustion of fossil fuels and other anthropogenic sources is a major source of PAHs in both road runoff and sediment [5,6,20,22,38]. The results from GC/MS laboratory analyses suggest a full range of PAH compounds in road runoff at both sampling sites including lighter (LMW) with molecular weight $<230$ and two to three rings, and heavier (HMW) with molecular weight $>230$ and four to six rings. The results of this study are consistent with the findings of previous studies suggesting that pyrogenic sources dominate the delivery of PAHs to urban stormwater [5,6,18-20,22,23, $38,39]$. We found that HMW PAHs comprised $88 \%$ to $93 \%$ of the total PAHs in road runoff at both sites. We found that the percentage of HMW PAHs was slightly higher at the end of the dry season at the site with higher AADT, while the percentage of LMW PAHs was higher at the site with lower AADT.

The fluoranthene to pyrene $(\mathrm{F} / \mathrm{P})$ ratios for both water samples and sediment indicate that pyrolytic sources dominate PAHs inputs to road runoff.

The $\mathrm{F} / \mathrm{P}$ ratios ranged from 1.16 to 1.25 for water samples, and from 1.22 to 1.25 for sediment samples. The calculated phenanthrene to anthracene $(\mathrm{P} / \mathrm{A})$ ratio for the water samples ranged from 8.36 to 9.74 . An exception was observed at Site 2 during the storm event of 04/30/ 2011 where a P/A ratio of 15.22 was calculated. These ratios indicate that petrogenic sources of various origins might be present at the site.

\subsection{Variability in PAHs Composition Profiles}

An important objective of this study was to determine whether water samples collected at the end of the wet and at the end of the dry season exhibit similar or distinct PAHs profiles. Table 2 summarizes the results of the Friedman's test for PAHs profiles measured in water samples taken at the end-of-wet and end-of-dry seasons. The Friedman's test yielded a value for the Q-statistic of 4.99 ( $p$-value $=0.08)$ for the 40 detected PAHs at site 1 and a value of $2.50(p$-value $=0.11)$ for the 40 detected PAHs at site 2. Both test results are not significant at $\alpha=$ 0.05 . Thus, we accept that the null hypothesis as true and conclude that the proportional distribution of PAHs in water samples taken at the end of the wet season is not significantly different from the proportional distribution of PAHs in water samples taken at the end of the dry season for both sites. The Friedman's test results for the 16 PAHs identified by EPA as Priority Pollutants indicate similarly that there is no statistically significant difference between PAH profiles at the end of the wet and end of the dry seasons. The test generated a $\mathrm{Q}$ test statistic value of 2.38 ( $p$-value $=0.30)$ for Site 1 and a $Q$ test statistic value of $1.00(p$-value $=0.32)$ for Site 2 which clearly indicate that the null hypothesis of similarity of distributions should be accepted at virtually any significance level.

The results from the statistical analysis also indicate that the distribution of HMW PAHs in the water column at the end of the wet season is not significantly different from the HMW PAH distribution in water samples taken at the end of the dry season (a $p$-value of 0.67 for Site 1 and a $p$-value of 0.23 for Site 2 , respectively). These results confirm findings from previous studies. Menzie et al. [20] found similarity in PAH profiles in water samples taken from each representative land use category included in the analysis. Pathiratne et al. [22] found similar PAH distribution in the samples obtained from road runoff at two sites with different traffic intensities.

The statistical analysis, however, shows a statistically significant dissimilarity for lower molecular weight $(2-3$

Table 2. Friedman's test results for PAH profiles in water samples collected at the end-of-wet and end-of-dry seasons.

\begin{tabular}{|c|c|c|c|c|}
\hline \multirow{2}{*}{$\begin{array}{c}\text { Datasets } \\
\text { Water column }\end{array}$} & \multicolumn{2}{|c|}{ Site 1} & \multicolumn{2}{|c|}{ Site 2} \\
\hline & Q test statistic & $p$-value & Q test statistic & $p$-value \\
\hline 40 PAHs & 4.99 & $p \leq 0.082$ & 2.50 & $p \leq 0.114$ \\
\hline 16 PAHs & 2.38 & $p \leq 0.304$ & 1.00 & $p \leq 0.317$ \\
\hline LMW PAH & 21.07 & $p \leq 0.000$ & 15.70 & $p \leq 0.000$ \\
\hline HMW PAH & 0.78 & $p \leq 0.677$ & 1.47 & $p \leq 0.225$ \\
\hline
\end{tabular}


rings) PAHs in water samples. The test generated a $\mathrm{Q}$ test statistic value of 21.07 ( $p$-value $=0.0003$ ) for Site 1$)$, and a Q test statistic value of $15.70(p$-value $=0.00007)$ for Site 2) These results indicate a statistically significant difference between LMW PAHs profiles at the end of the wet dry seasons. Possible explanation can be found in the processes of chemical breakdown of PAHs depending on their physical and chemical properties, the type of sorption surfaces (e.g., soil and sediment), and exposure to photochemical reagents [40]. Several LMW PAH including anthracene, benzo $(a)$ pyrene, and pyrene are known to be susceptible to reactions with hydroxyl radicals and are in most cases degraded faster than the highly hydrophobic PAHs with four to six fused rings [40].

\section{Conclusions}

This study investigated PAH contamination in road runoff with respect to the temporal and spatial distribution of PAH species. The study found higher PAHs levels in samples collected at both sites after an extended and drier than normal dry season. The estimated flow-weighted mean concentrations for the sampled storm events lead to similar conclusions. The relative magnitude of the estimated PAH mass-loading rates were found to be higher at the end of the dry season. The results indicated that higher PAH concentrations measured at the beginning of the storm event were not always indicative of a first flush. A storm first flush was found to occur inconsistently throughout the sampled storm events. The results also indicated that site characteristics, rainfall patterns and intensity, flow volume and antecedent dry period affected the mobilization and remobilization of pollutants and therefore played a role in PAHs delivery to receiving waters. The importance of the length of time between subsequent storm events available for pollutants to build up on impervious surfaces, identified by previous studies, was confirmed by this investigation.

The effect of the annual average daily traffic on PAHs concentrations in water samples requires further investigation. The continuous accumulation and wash-off of pollutants appeared to affect measured concentrations more than the traffic intensity. We found higher total PAHs concentrations in runoff samples at the site with the lower traffic intensity compared to the site with heavier traffic at the beginning of the dry season. Conversely, we found lower total PAH concentrations in runoff samples at the same site at the beginning of the wet season compared to the PAH levels at the site with higher AADT counts. Zhang et al. [6] reported higher PAH concentrations at sites with lower traffic volumes and suggested that factors beyond the level of service such seasonality in rainfall patterns and site characteristics exerted strong in- fluence on the level of PAHs concentrations in road runoff samples. A limitation of this study is that it does not account for the effect of the BMPs and pretreatment measures that could reduce PAH discharges before they reach receiving waters. There appears to be a need for future studies evaluating the feasibility of treating the first flush fraction of the storm after prolonged dry periods.

\section{Acknowledgments}

This study was supported through a grant by the FAU Environmental Sciences Everglades Fellowship Program funded by the National Park Service under Task Agreement J5284-09-0004, Cooperative Agreement H5000-060103. The findings and opinions reported are those of the authors and do not necessarily reflect the views of the funding agencies. We wish to acknowledge the contribution of Sarah Bellmund and Brigette Castro from Biscayne National Park who guided us in refining the methodology and selecting the sampling sites. We also acknowledge the valuable support of Adolfo Fernandez and Ingrid Ley from the Department of Chemistry \& Biochemistry and Southeast Environmental Research Center (SERC) at Florida International University; Ricardo Salazar and Larry W. Minor of the Florida Department of Transportation, District 6; and Steven Blair and Forest Shaw of the Department of Environmental Resources Management of Miami-Dade County.

\section{REFERENCES}

[1] I. D. Bossert and R. Bartha, "Structure-Biodegradability Relationships of Polycyclic Aromatic Hydrocarbons in Soil," Bulletin of Environmental Contamination and Toxicology, Vol. 37, No. 1, 1986, pp. 490-495. doi:10.1007/BF01607793

[2] M. Kayhanian and M. K. Stenstrom, "First-Flush Characterization for Stormwater Treatment," Stormwater, 2008. http://www.stormh2o.com/march-april-2008/pollutants-ru n-off.aspx

[3] L. H. Kim, M. Kayhanian, K.-D. Zoh and M. K. Stenstrom, "Modeling of Highway Stormwater Runoff," Science of the Total Environment, Vol. 348, No. 1-3, 2005, pp. 1-18. doi:10.1016/j.scitotenv.2004.12.063

[4] J. Soller, J. Stephenson, K. Olivieri, J. Downing and A. W. Olivieri, "Evaluation of the Seasonal Scale First Flush Pollutant Loading and Implications for Urban Runoff Management," Journal of Environmental Management, Vol. 76, 2005, pp. 309-318.

[5] E. D. Stein, L. L. Toefenthaler and K. Schiff, "Watershed-Based Sources of Polycyclic Aromatic Hydrocarbons in Urban Stormwater," Environmental Toxicology and Chemistry, Vol. 25, No. 2, 2006, pp. 373-385.

[6] W. Zhang, S. Zhang, D. Yue, C. Wan, Y. Ye and X. Wang, "Characterization and Loading Estimation of Polycyclic 
Aromatic Hydrocarbons in Road Runoff from Urban Regions of Beijing, China," Environmental Toxicology and Chemistry, Vol. 27, No. 1, pp. 31-37. doi:10.1897/07-030.1

[7] C. M. Teaf, D. J. Covert and S. R. Kothur, "Urban Polycyclic Aromatic Hydrocarbons (PAHS): A Florida Perspective," Proceedings of the Annual International Conference on Soils, Sediment, Water and Energy, Vol. 13, No. 1, 2008, Article 23.

[8] D. J. McKenzie and G. A. Irwin, "Water-Quality Assessment of Stormwater Runoff from a Heavily Used Urban Highway Bridge in Miami, Florida," USGS Water Resources Investigations 83-4153 (FHWA/FL/BMR-84270), 1983.

[9] E. F. Corcoran, M. S. Brown, F. R. Baddour, S. A. Chasens and A. D. Freay, "Biscayne Bay Hydrocarbon Study," NOAA Technical Memorandum NOS NCCOS 9, University of Miami RSMAS TR 2005-01, Coastal and Estuarine Data Archeology and Rescue Program, 1983.

[10] K. H. Haag, R. L. Miller, L. A. Bradner and D. S. McCulloch, "Water-Quality Assessment of Southern Florida: An Overview of Available Information on Surface and Ground-Water Quality and Ecology," US Geological Survey, Water-Resources Investigations Report 96-4177, Tallahassee, 1996.

[11] A. Y. Cantillo, G. G. Lauenstein and T. P O'Connor, "Mollusc and Sediment Contaminant Levels and Trends in South Florida Coastal Waters," Marine Pollution Bulletin, Vol. 34, No. 7, 1997, pp. 511-521. doi:10.1016/S0025-326X(96)00152-X

[12] V. G. Caccia and J. N. Boyer, "Spatial Patterning of Water Quality in Biscayne Bay, Florida as a Function of Land Use and Water Management," Marine Pollution Bulletin, Vol. 50, No. 11, 2005, pp. 1416-1429. doi:10.1016/j.marpolbul.2005.08.002

[13] T. L. Seal, F. D. Calder, G. M. Sloane, S. J. Schropp and H. L. Windom, "Florida Coastal Sediment Contaminants Atlas," Florida Department of Environmental Protection, Tallahassee, 1994.

[14] E. R. Long, G. Sloane, G. Scott, B. Thompson, R. S. Carr, J. Biedenbach, T. Wade, B. Presley, K. Scott, C. Mueller, G. Breken-Fols, B. Albrecht, J. W. Anderson and G. T. Chandler, "Magnitude and Extent of Chemical Contamination and Toxicity in Sediments of Biscayne Bay and Vicinity," NOAA Technical Memorandum 141, 2000.

[15] E. R. Long, M. J. Hameedi, G. M. Sloane and L. B. Read, "Chemical Contamination, Toxicity, and Benthic Community Indices in Sediments of the Lower Miami River and Adjoining Portions of Biscayne Bay, Florida," Estuaries, Vol. 25, No. 4A, 2002, pp. 622-637. doi:10.1007/BF02804895

[16] M. K. Stenstrom and M. Kayhanian, "First Flush Phenomenon Characterization," CTSW-RT-05-73-02.6, Prepared for the California Department of Transportation Division of Environmental Analysis, 2005.

[17] A. Krein and M. Schorer, "Road Runoff Pollution by Polycyclic Aromatic Hydrocarbons and Its Contribution to
River Sediments," Water Research, Vol. 34, No. 16, 2000, pp. 4110-4115.

[18] E. J. Hoffman, G. L. Mills, J. S. Latimer and J. G. Quinn, "Urban Runoff as a Source of Polycyclic Aromatic Hydrocarbons to Coastal Waters," Environmental Science and Technology, Vol. 18, No. 8, 1984, pp. 580-587. doi:10.1021/es00126a003

[19] B. Ngabe, T. F. Bidleman and G. I. Scott, "Polycyclic Aromatic Hydrocarbons in Storm Runoff from Urban and coastal South Carolina," The Science of the Total Environment, Vol. 255, No. 1-3, 2000, pp. 1-9. doi:10.1016/S0048-9697(00)00422-8

[20] C. A. Menzie, S. S. Hoeppner, J. J. Cura, J. S. Freshman and E. N. LaFrey, "Urban and Suburban Storm Water Runoff as a Source of Polycyclic Aromatic Hydrocarbons (PAHs) to Massachusetts Estuarine and Coastal Environments," Estuaries, Vol. 25, No. 2, 2002, pp. 165-176. doi:10.1007/BF02691305

[21] H. M. Hwang and G. D. Foster, "Characterization of Polycyclic Aromatic Hydrocarbons in Urban Stormwater Runoff Flowing into the Tidal Anacostia River," Environmental Pollution, Vol. 140, No. 3, 2006, pp. 416-426. doi:10.1016/j.envpol.2005.08.003

[22] K. A. S. Pathiratne, O. C. P. de Silva, D. Hehemann, I. Atkinson and R. Wei, "Occurrence and Distribution of Polycyclic Aromatic Hydrocarbons (PAHs) in Bolgoda and Beira Lakes, Sri Lanka," Bulletin of Environmental Contamination and Toxicology, Vol. 79, No. 2, 2007, pp. 135-140. doi:10.1007/s00128-007-9092-Z

[23] E. J. Hoffman, J. S. Latimer, C. D. Hunt, G. L. Mills and J. G. Quinn, "Stormwater Runoff from Highways," Water, Air, and Soil Pollution, Vol. 25, No. 4, 1985, pp. 349364. doi:10.1007/BF00283788

[24] E. Hong, E. A. Seagren and A. P. Davis, "Sustainable Oil and Grease Removal from Synthetic Stromwater Runoff Using Bench-Scale Bio-Retention Studies," Water Environment Research, Vol. 78, No. 2, 2006, pp. 141-155. doi:10.2175/106143005X89607

[25] J. J. Sansalone and S. G. Buchberger, "Partitioning and First Flush of Metals in Urban Roadway Stormwater," Journal of Environmental Engineering, Vol. 123, No. 2, 1997, pp. 134-143. doi:10.1061/(ASCE)0733-9372(1997)123:2(134)

[26] J.-L. Bertrand-Krajewski, G. Chebbo and A. Saget, "Distribution of Pollutant Mass vs Volume in Stormwater Discharges and the First Flush Phenomenon," Water Research, Vol. 32, No. 8, 1998, pp. 2341-2356. doi:10.1016/S0043-1354(97)00420-X

[27] A. Deletic, "The First Flush Load of Urban Surface Runoff," Water Research, Vol. 32, No. 8, pp. 2462-2470. doi:10.1016/S0043-1354(97)00470-3

[28] M. Kayhanian, A. Singh, C. Suverkropp and S. Borrum, "Impact of Annual Average Daily Traffic on Highway Pollutant Concentrations," Journal of Environmental Engineering, Vol. 129, No. 11, 2003, pp. 975-990. doi:10.1061/(ASCE)0733-9372(2003)129:11(975) 
[29] J. H. Lee and K. W. Bang, "Characterization of Urban Stormwater Runoff," Water Research, Vol. 34, No. 6, 2000, pp. 1773-1780. doi:10.1016/S0043-1354(99)00325-5

[30] B. Suderman and N. H. Marcus, "The Effects of Orimulsion and Fuel Oil \#6 on the Hatching Success of Copepod Resting Eggs in the Seabed of Tampa Bay, Florida," Environmental Pollution, Vol. 120, No. 3, 2002, pp. 787795.

[31] J. Obeysekera, J. Browder, L. Horning and M. A. Harwell, "The Natural South Florida System I: Climate, Geology, and Hydrology," Urban Ecosystems, Vol. 3, No. 3-4, 1999, pp. 223-244. doi:10.1023/A:1009552500448

[32] National Oceanic and Atmospheric Administration-National Weather Service (NOAA-NWS), "Duration of Summer Season in South Florida," Miami-South Florida Weather Forecast Office, Miami, 2010.

http://www.srh.noaa.gov/mfl/summer_season

[33] Florida Department of Transportation FDOT, "Geographic Information System (GIS): GIS Shapefiles,” 2010. http://www.dot.state.fl.us/planning/statistics/gis/trafficdata. shtm

[34] US Environmental Protection Agency (USEPA), "NPDES Storm Water Sampling Guidance Document," EPA 833-892-001, Office of Water, Washington DC, 1992.

[35] J. H. Lee, S. L. Lau, M. Kayhanian and M. K. Stenstrom, "Seasonal First Flush Phenomenon of Urban Stormwater Discharges," Water Research, Vol. 38, No. 19, 2004, pp.
4153-4163. doi:10.1016/j.watres.2004.07.012

[36] P. Leftwich, D. Zierden and M. Griffin, "Monthly Climate Summaries for Florida," Florida Climate Center, Office of the State Climatologist, Florida State University, Tallahassee, 2009-2011.

[37] J. H. Lee, K. W. Bang, L. H. Ketchum, J. S. Choe and M. J. Yu, "First Flush Analysis of Urban Storm Runoff," Science of the Total Environment, Vol. 293, No. 1-3, 2002, pp. 163-175. doi:10.1016/S0048-9697(02)00006-2

[38] E. D. Stein, L. L. Tiefenthaler and K. C. Schiff, "Comparison of Stromwater Pollutant Loading by Land Use Type," Southern California Coastal Water Research Project, AR08-015-027, 2008.

http://www.sccwrp.org/Documents/AnnualReports/Brows eAllAnnualReports/2008AnnualReport.aspx.

[39] M. K. Stenstrom, G. S. Silverman and T. A. Bursztynsky, "Oil and Grease in Urban Stormwaters," ASCE Journal of the Environmental Engineering Division, Vol. 110, No. 1, 1984, pp. 58-72. doi:10.1061/(ASCE)0733-9372(1984)110:1(58)

[40] S. Jonsson, Y. Persson, S. Frankki, B. van Bavel, S. Lundstedt, P. Haglund and M. Tysklind, "Degradation of Polycyclic Aromatic Hydrocarbons (PAHs) in Contaminated Soils by Fenton's Reagent: A Multivariate Evaluation of the Importance of Soil Characteristics and PAH Properties," Journal of Hazardous Materials, Vol. 149, No. 1, 2007, pp. 86-96. 